\title{
Synthesis of Benzenesulfonamide Derivatives Via Ring Opening of Aziridines In The Presence of Magnetically Retrievable Graphene Based (CoFe@rGo) Nanohybrid.
}

\section{Ankush Sheoran}

Department of Chemistry \& Centre of Advanced Studies in Chemistry, Panjab University

Komal

Department of Chemistry \& Centre of Advanced Studies in Chemistry, Panjab University Jaspreet Kaur

Energy Research Centre, Panjab University

\section{Paramdeep Kaur}

Department of Chemistry \& Centre of Advanced Studies in Chemistry, Panjab University Jyoti Agarwal

Department of Chemistry \& Centre of Advanced Studies in Chemistry, Panjab University Sonal Singhal ( $\square$ sonal1174@gmail.com )

Department of Chemistry \& Centre of Advanced Studies in Chemistry, Panjab University

\section{Research Article}

Keywords: Graphene based nanohybrid, magnetic nanocatalyst, heterogeneous catalyst, aziridine ring opening, benzenesulfonamide derivatives products

Posted Date: September 3rd, 2021

DOI: https://doi.org/10.21203/rs.3.rs-851825/v1

License: (a) (i) This work is licensed under a Creative Commons Attribution 4.0 International License. Read Full License

Version of Record: A version of this preprint was published at Journal of Inorganic and Organometallic Polymers and Materials on January 12th, 2022. See the published version at https://doi.org/10.1007/s10904-021-02216-6. 


\section{Abstract}

Graphene based magnetic nanohybrids have engrossed considerable research curiosity because of their exceptional properties and diverse applications associated with green chemistry. In this regard, a practical, facile and regioselective preparation of 1,2-diamines from $N$-tosylaziridine/(S)-(+)-2-Benzyl-1-( $p$ tolylsulfonyl)aziridine and aryl amines in the presence of magnetically separable graphene based nanohybrid (CoFe@rGO) has been proposed under mild and solvent free conditions. The FT-IR, FE-SEM, XRD and EDX spectroscopic analysis confirmed the formation of the CoFe@rGo nanohybrids. For unsymmetrical aziridine, nucleophilic attack of aryl amines was observed to take place selectively at the more substituted carbon atom of aziridine ring. Environmentally benign, efficient, shorter reaction time, solvent-free conditions, low catalyst loading, excellent reaction yields and reusability of the catalyst for six consecutive runs without significant loss in its activity are the key advantages of this protocol.

\section{Highlights}

- Synthesis of Graphene based magnetic nanohybrids (CoFe@rGo) using hydrothermal technique.

- Enhanced catalytic performance owing to large surface areas and active catalytic sites.

- Magnetically retrievable catalyst displaying great recyclability.

- Aziridine ring opening reactions with amines under solvent free conditions.

\section{Introduction}

Sulfonamides are a significant class of compounds displaying a wide variety of biological activities such as anti-fungal, anti-bacterial, anti-thyroid, anti-inflammatory and anti-viral etc. (Fig. 1) [1]. Particularly because of the unique functional groups present in their structure, they are extensively utilized in organic materials, agriculture and dyes [2]. They are generally used in veterinary medicines for therapeutic purposes to combat bacterial diseases [3].

Sulfonamides employ their effect by targeting on dihydropteroate synthase (DHPS) enzyme, which catalyzes folic acid pathway in bacteria [4]. Therefore, they are commonly utilized for their broad spectrum of antibacterial activity. Because of the substantial significance of sulfonamides, there are various reports available in literature for their synthesis via different methodologies. However, efficient, environmentally benign, and green approach for the synthesis of sulfonamides from cheap and easily available starting materials is still desirable. One of the most straightforward synthetic approaches for the synthesis of sulfonamides derivatives is via ring opening of aziridines.

Aziridines are three membered heterocyclic compounds, usually employed as intermediates for various organic transformations [5]. Substituted aziridines such as $\mathrm{N}$-arylsulfonyl aziridines in particular, have attracted considerable attention because of their susceptibility towards regio and stereoselective nucleophilic ring opening and ring expansion reactions [6-10]. The nucleophilic ring opening of aziridines has been utilized to synthesize biologically active compounds such as alkaloids, heterocycles and amino 
acids [11]. Aziridines yield vicinal diamines with nitrogen nucleophiles such as amines, which are components of many biologically important compounds [12]. Therefore, there are several catalytic systems reported in the literature for ring opening of aziridines with various nucleophiles. Very recently, Liu et al. [13] employed zinc based catalytic system for the regioselective ring opening of 2, 3-aziridinyl alcohols using aromatic amines and thiophenols as nucleophiles. Ghorai and co-worker, [14] reported an efficient synthesis of biologically important imidazoline and oxazolidines via ring opening of the activated aziridines and epoxides with various amines, and a subsequent condensation with aldehydes under mild reaction conditions. Bera et al. [15] reported $\left[\mathrm{Ag}(\mathrm{COD})_{2}\right] \mathrm{PF}_{6}$ catalyzed ring opening reaction of $\mathrm{N}$-tosylaziridines and azetidines with alcohols, amines, thiols and related tethered dinucleophiles. Similarly, Zhang et al. [16] synthesized a-amino aryl ketones via methylquinoline promoted ring opening of $\mathrm{N}$-sulfonyl aziridines with dimethyl sulfoxide (DMSO). Despite their specific selectivity and efficiency for ring opening of aziridines, majority of these methodologies experience several drawbacks such as use of expensive and hazardous reagents, non-recyclable catalysts, use of volatile and toxic solvents, extensive reaction time, long reaction times, harsh reaction conditions, tedious workup procedures and low product yields $[17,18]$. Therefore, the exploration of such protocol which is energy efficient, environmentally benign, facile, solvent free, and apparently separable are the current need of hour for the ring opening of aziridines.

In this regard, nano catalysis, which involves nanoparticles as heterogeneous catalysts has came to the forefront for carrying out various organic transformations in an environmentally benign manner. For this purpose, a diverse array of nanomaterials such as transition metals, transition metal oxides, composites of metals with organic moieties and carbon based nanostructures have been employed as versatile heterogeneous catalyst due to the several interesting properties such as high surface to volume ratio, great selectivity, high stability, surface modifiability, great biocompatibility etc. [19, 20].

Nowadays, carbon nanomaterials, in particular, the ones based on graphene have acquired enormous attention from material science and catalysis chemists; as a viable catalyst to carry out several organic transformations. Amongst these materials, reduced Graphene oxide ( $\mathrm{rGO}$ ), has emerged as an excellent heterogeneous catalyst, because of its remarkable characteristics such as large specific surface area, high thermal stability, exceptional structural and electronic properties. Interestingly, rGO possesses several polar functional groups such as hydroxyl, epoxy and carboxyl groups, which imparts hydrophilicity and water solubility to $\mathrm{rGO}[21-23]$. Therefore, $\mathrm{rGO}$ has proved to be a competent material for a wide range of catalytic reactions such as Friedel-Craft acylation, hydrogenation, ring opening reaction of epoxides, oxidation-reduction reactions, aerobic oxidation of alcohol etc. [24-26]. However, the separation of rGO from the reaction mixture without causing any secondary pollution has remained a challenge for research community [27]. The recyclability problem can be well addressed by amalgamation of magnetic nanoparticles with $\mathrm{rGO}$, resulting in the fabrication of environmentally benign nanohybrid with simplified isolation of product, facile recovery and recyclability of catalyst [28]. The incorporation of magnetic nanoparticles with rGO not only provides magnetic nature to nanohybrid but 
also enhances catalytic performance of nanohybrid due to the synergistic interactions between the rGO and magnetic nanoparticles.

In the present work, graphene based magnetically retrievable (CoFe@rGO) nanohybrid has been synthesized via easy and scalable hydrothermal method. For the first time, CoFe@rGo nanohybrid has been utilized as promising heterogeneous catalyst for the one step construction of benzensulfonamides derivatives via ring opening reaction of $N$-Tosylaziridine and $(S)-(+)-2$-Benzyl-1-( $p$-tolylsulfonyl) aziridine with different aromatic amines under solvent free conditions. The catalyst drove the reaction to completion in 9-24 min and afforded good yield (64-92\%). As compared to other conventional catalysts, CoFe@rGo nanohybrid exhibited better stability, negligible leaching, good recyclability, and no deactivation of the nanohybrid catalyst.

\section{Experimental Section}

\subsection{Materials used}

Potassium permanganate $\left(\mathrm{KMnO}_{4}\right)$, Ferric nitrate nonahydrate $\left(\mathrm{Fe}\left(\mathrm{NO}_{3}\right)_{3} \cdot 9 \mathrm{H}_{2} \mathrm{O}, 98 \%\right)$ and Cobalt nitrate hexahydrate $\left(\mathrm{Co}\left(\mathrm{NO}_{3}\right)_{3} \cdot 6 \mathrm{H}_{2} \mathrm{O}, 98 \%\right)$ were obtained from Central Drug House $(\mathrm{CDH})$. Hydrogen peroxide $\left(\mathrm{H}_{2} \mathrm{O}_{2}, 30 \% \mathrm{w} / \mathrm{v}\right)$ and Sodium nitrate $\left(\mathrm{NaNO}_{3}\right)$ were purchased from Fisher scientific, and Graphite flakes were purchased from Otto chemicals. Liquor ammonia ( $\mathrm{Liq}$. $\left.\mathrm{NH}_{3}\right)$ and Sulphuric acid $\left(\mathrm{H}_{2} \mathrm{SO}_{4}\right)$ and were obtained from Merck. N-Tosylaziridine and (S)-(+)-2-Benzyl-1-(p-tolysulfonyl) were obtained from Sigma Aldrich. All the other mentioned chemicals were of analytical grade and were used as bought without any further refining. All the solutions were prepared in deionized water obtained from an ultrafiltration system (Milli-Q, Millipore).

\subsection{Synthesis of nanocatalysts}

\subsubsection{Synthesis of graphene oxide (GO)}

Graphene oxide (GO) was fabricated using graphite flakes as the starting substrate by following modified Hummer's method [29]. In a typical synthetic procedure, $3 \mathrm{~g}$ of graphite powder was mixed with $70 \mathrm{~mL}$ of concentrated $\mathrm{H}_{2} \mathrm{SO}_{4}$ under constant stirring at a temperature below $0{ }^{\circ} \mathrm{C}$ in order to avert overheating and explosion. Then, preset amount of $\mathrm{KMnO}_{4}(9 \mathrm{~g})$ and $\mathrm{NaNO}_{3}(1.5 \mathrm{~g})$ were introduced in to the reaction mixture in a duration of 30 min with simultaneous continual stirring while maintaining the temperature of the reaction mixture at $-4{ }^{\circ} \mathrm{C}$. The reaction mixture was then magnetically stimulated for an additional 24 $\mathrm{h}$ at room temperature. Afterwards, the reaction mixture was diluted by adding deionized water and ultimately $18 \mathrm{~mL}$ of $\mathrm{H}_{2} \mathrm{O}_{2}$ was gradually added to the reaction mixture in anticipation of the change of colour of the reaction mixture from brown to yellow, which stipulated the completion of oxidation of graphite to graphene oxide. The resultant mixture was washed several times with deionized water until the $\mathrm{pH}$ of the solution became neutral and the obtained product was then filtered and dried at $80^{\circ} \mathrm{C}$ for $10 \mathrm{~h}$. 


\subsection{Synthesis of CoFe@rGo nanohybrids}

A simplistic hydrothermal methodology was employed for the fabrication of CoFe@rGO nanohybrid as depicted in Scheme 1 [30]. In our previous work [24], cobalt ferrite and rGO based heterogeneous catalysts were examined for their catalytic activity for the ring opening of epoxides and it was inferred that $20 \mathrm{wt} \%$ loading of cobalt ferrite in rGO showcased best catalytic performance. So, for the present work, the relative quantity of cobalt ferrite was fixed to $20 \mathrm{wt} \%$ to that of GO. To fabricate the nanohybrid, graphene oxide (GO) was initially dispersed in deionized water utilizing ultrasonic technique. Then, stoichiometric amounts of metal nitrates $\left[\mathrm{Fe}\left(\mathrm{NO}_{3}\right)_{3}\right.$ and $\left.\mathrm{Co}\left(\mathrm{NO}_{3}\right)_{2} ; 0.02 \mathrm{M}\right]$ were dissolved in slightest amount of water, and $\mathrm{pH}$ of the solution was adjusted to 7.5 with liquid ammonia. Subsequently, aqueous graphene oxide (GO) suspension was added to the metal nitrate solution with continuous stirring for $2 \mathrm{~h}$.

The resulting solution was then transferred to a Teflon lined autoclave and the autoclave was kept at 160 ${ }^{\circ} \mathrm{C}$ for $15 \mathrm{~h}$ in a hot air oven. The obtained precipitates were systematically washed with acetone and deionized water and dried at $60^{\circ} \mathrm{C}$ overnight. The obtained nanohybrid was labelled as CoFe@rGo.

\subsection{Physical characterization techniques}

Several techniques were employed for the characterization of the synthesized CoFe@rGO nanohybrid. The crystallographic structure of the catalyst was examined on a Panalytical's X'pert Pro X-ray

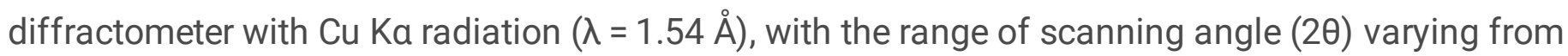
$10^{\circ}-80^{\circ}$. In order to confirm the functional groups present in the synthesized materials, Fourier Transform Infra-red (FT-IR) spectra were recorded on a Perkin-Elmer Spectrum RX-IFTIR spectrophotometer in the scan range of $4000-400 \mathrm{~cm}^{-1}$. The samples were prepared with $\mathrm{KBr}$ pellets. The surface morphology of the material was characterized by Field Emission Scanning Electron Microscopy (FE-SEM, HitachiSU8010). The specific surface area of the nanohybrid was obtained by using Brunauer-Emmett-Teller (BET) surface area analyser ((11-2370) Gemini, Micromeritics, USA). The magnetic studies were performed using vibrating sample magnetometer (MicroSense EZ7).

Thin layer chromatography (TLC) was performed by using pre-coated silica $60 \mathrm{~F} 254,0.25 \mathrm{~mm}$ aluminium plates (purchased from Merck) and the progress of the reactions was visualized and studied under UV chamber. The efficacious fabrication of desired product was confirmed by Nuclear Magnetic Resonance (NMR) spectrometer (BRUKER AVANCE II $400 \mathrm{MHz}$ ) utilizing $\mathrm{CDCl}_{3}$ as solvent and TMS as an internal standard.

\subsection{Catalytic assessment}

Pristine GO as well as CoFe@rGo nanohybrid were employed for the catalytic study of the ring opening of $\mathrm{N}$-Tosylaziridine and (S)-(+)-2-Benzyl-1-(p-tolylsulfonyl) aziridine with aromatic amines. The reactions were performed between equimolar amounts of amine $(1 \mathrm{mmol})$ and aziridine $(1 \mathrm{mmol})$ in the presence of GO and CoFe@@GO nanohybrid as catalyst $(10 \mathrm{mg})$ at $80^{\circ} \mathrm{C}$ under solvent-free conditions. The progress of the reaction was monitored by thin layer chromatography. After the consumption of the starting materials, the catalysts were separated from the reaction mixture by external magnet, washed 
with deionized water and acetone to remove the organic or inorganic part from the catalysts. The recovered catalysts were dried and recycled for next cycle. The final isolated products were characterized by ${ }^{1} \mathrm{H}$ NMR.

\section{Results And Discussion}

\subsection{Characterization of the nanohybrid}

\subsubsection{FT-IR spectroscopy}

FT-IR spectra aids in the identification of different functional groups existing in the crystal lattice of catalysts by analyzing and examining their particular vibrational modes. FTIR technique was therefore used to confirm the presence of oxygen containing functionalities in $\mathrm{GO}$ and their variations after the formation of nanohybrid. The FT-IR spectra of pure GO and CoFe@rGO nanohybrid are shown in Fig. 2. A broad peak around $3400 \mathrm{~cm}^{-1}$ was observed, which could be ascribed to the stretching vibration of O-H bonds of carboxyl and hydroxyl moieties existing in the structure of GO. Moreover, the characteristic peaks around $1725,1620,1415,1220$ and $1088 \mathrm{~cm}^{-1}$ were observed, which could be assigned to stretching modes of $\mathrm{C}=0$, aromatic $\mathrm{C}=\mathrm{C}$, carboxyl $\mathrm{C}-\mathrm{O}$, epoxy $\mathrm{C}-\mathrm{O}$ and alkoxy group, respectively [31]. The spectra of CoFe@rGO nanohybrid shows all the characteristic peaks of GO, except the peaks around $1625-1725 \mathrm{~cm}^{-1}$ and $1150 \mathrm{~cm}^{-1}$ corresponding to the oxygen containing functional groups, which clearly indicates the complete reduction of GO to rGO. Additionally, a new peak around $590 \mathrm{~cm}^{-1}$ was observed, displaying the formation of metal oxygen bond in CoFe@rGO nanohybrid [32].

\subsubsection{Powder XRD analysis}

In order to determine the phase purity and structural parameters of the synthesized nanohybrid, powder XRD technique was utilized. The characteristic XRD patterns of GO and CoFe@rGO nanohybrid are presented in Fig. 3. A strong diffraction peak at $2 \theta=10.5^{\circ}$ corresponding to (011) crystal plane was observed in the case of GO. The diffraction peaks corresponding to (220), (311), (400), (511) and (440) planes were observed in the X-ray diffractogram corresponding to CoFe@rGO nanohybrid, establishing the construction of single phase cubic structure of $\mathrm{CoFe}_{2} \mathrm{O}_{4}$ with $\mathrm{Fd}-3 \mathrm{~m}$ space group. Additionally, diffraction peak corresponding to (011) plane was absent in the XRD pattern of CoFe@rGO, clearly indicating the complete reduction of $\mathrm{GO}$ to $\mathrm{rGO}[33,34]$. Though, the diffraction peak corresponding to rGO was not observed in the XRD pattern of the nanohybrid which could be attributed to the disorder and damage generated in its layered structure by the crystal development of ferrite nanoparticles in its interlayers [35-36]. The average crystallite size of the synthesized nanohybrid and of pristine GO were evaluated from the broadening of most intense peak i.e. the one corresponding to (311) plane employing Debye-Scherrer equation [37].

$D_{h k l}=k \lambda / \beta \cos \theta(1)$ 
Where $D_{h k l}$ is the crystallite size, $k$ is the Scherrer's constant with a value of $0.9, \lambda$ is the wavelength of radiation used, $\beta$ is the full width at half maxima of the diffraction peak (FWHM) and $\theta$ is the angle of diffraction. The values of crystallite size $\left(D_{\text {hkl }}\right)$ were observed to lie in the range of 7-12 nm as shown in Table 1. Le Bail refinement method was employed to compute the lattice parameter (a) values of the synthesized materials and results are summarized in Table 1.

Table 1

Crystallite size $D_{\text {hkl }}(n m)$ and Lattice parameter, a ( $\mathrm{A})$ for GO and CoFe@rGo nanohybrid.

\begin{tabular}{|llll|}
\hline Sample & $D_{\text {hkl }}( \pm 2 \mathrm{~nm})$ & $\mathrm{a}(\AA)$ \\
\hline Go & 7.7 & 8.320 \\
CoFe@rGo & 11.3 & 8.384 \\
\hline
\end{tabular}

\subsubsection{Morphological studies}

FE-SEM technique was exploited to visualize the morphological details and structure of the synthesized nanohybrid. The typical FE-SEM micrographs of CoFe@rGo nanohybrid at different nanometric resolutions are given in Fig. 4. FE-SEM micrographs display the layered structure of $\mathrm{rGO}$ with a random distribution of $\mathrm{CoFe}_{2} \mathrm{O}_{4}$ nanoparticles on the edges and surface sheets of graphene. Furthermore, FE-SEM micrographs of nanohybrid clearly indicate that $\mathrm{CoFe}_{2} \mathrm{O}_{4}$ nanoparticles remain adhered to the surface of rGO besides stirring and long period of sonication, signifying strong interaction between $\mathrm{CoFe}_{2} \mathrm{O}_{4}$ nanoparticles and rGO. Owing to the combined effect of large surface area and layered structure contributed by $\mathrm{rGO}$ in the nanohybrid, there occurs an enhancement in the exposure of active sites of nanoferrites, which eventually improves the catalytic efficiency of nanohybrid. [38-41].

Additionally, EDX spectra was recorded to confirm the elemental composition of the synthesized nanohybrid as shown in Fig. 4, which established the existence of desired elements only. The EDS pattern of sample unveiled the presence of $\mathrm{Co}, \mathrm{Fe}, \mathrm{O}$ and $\mathrm{C}$ corespondent with the elemental composition of cobalt ferrite and GO. The peak corresponding to $\mathrm{C}$ was instigated owing to the basal plane of $\mathrm{rGO}$, and the existence of $\mathrm{O}$ could be ascribed to the oxygen present in ferrite NPs and oxygen containing functional groups of rGO. No additional peaks corresponding to other elements were observed which further confirmed the purity of the synthesized nanohybrid. The elemental mapping of CoFe@orGo nanohybrid has been illustrated in Fig. 5 which disclosed the uniform distribution of all the essential elements present in the samples.

\subsubsection{Surface area investigation}

It is eminent that surface area is the most imperative factor for catalysis. Large surface area value of catalyst signifies the presence of more number of active sites for the catalytic reaction. BET analysis was performed for the determination of specific surface area of GO and the fabricated nanohybrid. Before 
BET analysis, the samples were preheated at $150^{\circ} \mathrm{C}$ for $1 \mathrm{~h}$ before $\mathrm{N}_{2}$ absorption. Afterwards, the values of total surface area $(\mathrm{S})$ and specific surface area $\left(\mathrm{S}_{\mathrm{BET}}\right)$ were calculated using following equations [42]

$S=Q_{m} N_{S} / V(1)$

$\mathrm{S}_{\mathrm{BET}}=\mathrm{S} / \mathrm{M}(2)$

The obtained values of specific surface area of GO and CoFe@ @rGO were $4.80 \mathrm{~m}^{2} \mathrm{~g}^{-1}$ and $51.80 \mathrm{~m}^{2} \mathrm{~g}^{-1}$, respectively. It can be clearly seen that the integration of $\mathrm{GO}$ and $\mathrm{CoFe}_{2} \mathrm{O}_{4}$ resulted in significant enhancement in the specific surface area value. The high specific surface area of the nanohybrid support the augmented catalytically active surface sites resulting in enhancement of catalytic efficancy [43]. The BET plots for GO and CoFe@rGO are shown in supplementary file as Fig. S23 and Fig. S24, respectively.

\subsubsection{Magnetic measurements}

The magnetic characteristics of the synthesized nanohybrid were examined by recording the room temperature hysteresis loop with the help of vibrating sample magnetometer as shown in Fig. 6 . The computed values of saturation magnetization $(M s)$, coercivity $\left(H_{c}\right)$, remanence $\left(M_{r}\right)$ and squareness ratio $\left(\mathrm{S}_{\mathrm{q}}\right)$ for the synthesized nanohybrid are listed in Table 2. The saturation magnetization value was observed to decrease in comparison to pure $\mathrm{CoFe}_{2} \mathrm{O}_{4}$ [44] with addition of $\mathrm{rGO}$ but still the sample was sufficiently magnetic to be facilely recovered with the help of an external magnet.

Table 2

Remanence $\left(M_{r}\right)$, coercivity $\left(H_{c}\right)$, squareness ratio $\left(S_{q}\right)$, saturation magnetization $\left(\mathrm{M}_{\mathrm{S}}\right)$ of the synthesized nanohybrid.

\section{Sample $\quad M_{r}(e m u / g) \quad H_{c}(0 e) \quad S_{q} \times 10^{-2} \quad M_{s}(e m u / g)$

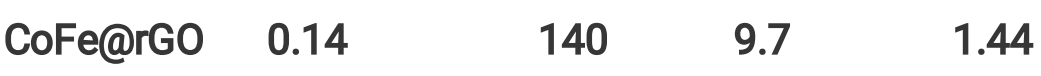 \\ 3.2. Catalytic investigation for aziridine ring opening}

In our previous study [45], optimizations of the reaction conditions were performed for the ring opening of epoxide with aniline in the presence of different magnetic nanoparticles $\left(\mathrm{MFe}_{2} \mathrm{O}_{4}, \mathrm{M}=\mathrm{Co}, \mathrm{Ni}, \mathrm{Cu}\right.$ and $\mathrm{Zn}$ ) synthesized by various techniques. Best results were obtained with $\mathrm{CoFe} \mathrm{O}_{4}$ nanoparticles synthesized by hydrothermal technique as it provided $100 \%$ conversion (GCMS) of reactants into corresponding amino alcohol within $5 \mathrm{~min}$. Keeping the proficient catalytic properties of $\mathrm{CoFe}_{2} \mathrm{O}_{4}$ nanoparticles in mind, herein, $\mathrm{CoFe}_{2} \mathrm{O}_{4}, \mathrm{GO}$ and CoFe@rGO were employed as heterogeneous catalysts for the ring opening of aziridines also, the so obtained results have been summarized in Table 3.

Ring opening reactions of aziridine were carried out between aziridine and different aromatic amines using $\mathrm{CoFe}_{2} \mathrm{O}_{4}, \mathrm{GO}$ and $\mathrm{CoFe} @ \mathrm{rGO}$ as heterogeneous catalysts at $80^{\circ} \mathrm{C}$ under solvent free conditions. The best results were obtained when CoFe@rGO nanohybrid was used as a catalyst since the reaction was 
completed in a comparatively shorter time duration as compared to $\mathrm{CoFe}_{2} \mathrm{O}_{4}$ and $\mathrm{GO}$ nanoparticles. The scope of the protocol was probed for different aryl amine substrates with $N$-tosylaziridine as shown in Table 3. Distinct aryl amines having electron releasing as well as withdrawing groups on the ring were tested. The desired ring opening products were obtained with good to excellent yields within a very few minutes. The reactions were very quick in case of aryl amines having electron releasing groups such as $p$ $\mathrm{OCH}_{3}$ and $p-\mathrm{CH}_{3}$ group on the aryl ring (Table 3, amines $\left.1 \mathbf{h}, 1 \mathbf{i}\right)$. Aryl amines having electron withdrawing groups such as $p-\mathrm{Cl}, p$ - $\mathrm{Br}$ and $p$-I group on the aryl ring took little longer to undergo ring opening reactions (Table 3 , amines $1 \mathbf{c}, \mathbf{1 e}$, and $\mathbf{1 g}$ ). In addition, the ring opening of aziridine with hindered aryl amines such as 2-chloroaniline, 2-bromoaniline and 2-iodoaniline were also studied which gave the corresponding products in good to excellent yields (Table 3 , amines $\mathbf{1 b}, \mathbf{1} \mathbf{d}$ and $\mathbf{1} \mathbf{f}$ ). Further, in case of aromatic amines $(1 \mathbf{j}-1 \mathbf{k})$, the reaction was observed to be really fast which can be credited to increased resonance in these compounds. The ${ }^{1} \mathrm{H}$ NMR spectra of products $3 a-k$ are given in supplementary file as Fig. S1-S11.

Table 3. Reaction completion time and \% yield for the ring opening of $N$-tosylaziridine (2) with various aromatic amines (1a-k) in the presence of $\mathrm{CoFe}_{2} \mathrm{O}_{4}, \mathrm{GO}$ and CoFe@rGO nanohybrid ${ }^{\mathrm{a}}$. 


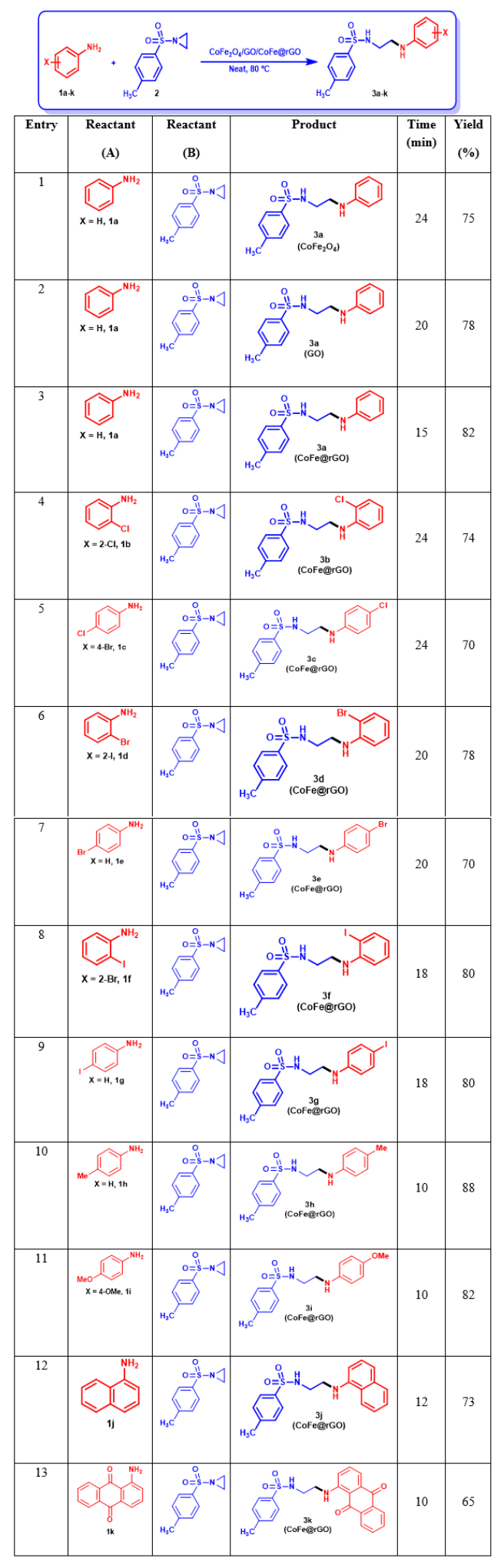

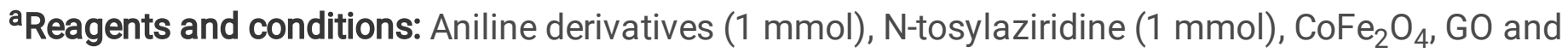
CoFe@rGo nanoparticles (10 mg).

With successful completion of the ring opening of aziridine, similar methodology was applied for the regioselective ring opening of chiral $(S)-(+)-2$-Benzyl-1-( $p$-tolylsulfonyl)aziridine $\mathbf{4}$ under solvent free conditions (Table 4). 
For unsymmetrical aziridine 4, regioselective nucleophilic substitution of aryl amines occured at the more substituted aziridine site due to the presence of electron releasing benzyl group which stabilizes the compound during $\mathrm{N}-\mathrm{C}$ bond cleavage. The substrate scope of this ring opening reaction was investigated by using unsymmetrical aziridine 4 and various aryl amines (1a-1k) as shown in Table 4. Again, different aryl amines having electron releasing as well as withdrawing groups on the ring were tested. It was observed that the reaction time for the ring opening of aziridine was shorter for aryl amines with electron releasing group such as $p-\mathrm{OCH}_{3}$ and $p-\mathrm{CH}_{3}$ group on the aryl ring (Table 4, amines $\mathbf{1 h}-\mathbf{1} \mathbf{i}$ ). Aryl amines with electron withdrawing group such $p-\mathrm{Cl}, p$ - $\mathrm{Br}$ and $p$-I group on the aryl ring took little longer to undergo ring opening reactions (Table 4 , amines $1 \mathrm{c}, 1 \mathbf{e}$, and $\mathbf{1 g}$ ).

Table 4. Reaction completion time and \% yield for the ring opening of $(S)-(+)-2-B e n z y l-1-(p-$ tolylsulfonyl)aziridine (4) with various aromatic amines (1a-k) in the presence of $\mathrm{CoFe}_{2} \mathrm{O}_{4}, \mathrm{GO}$ and CoFe@rGo nanohybrid ${ }^{a}$. 


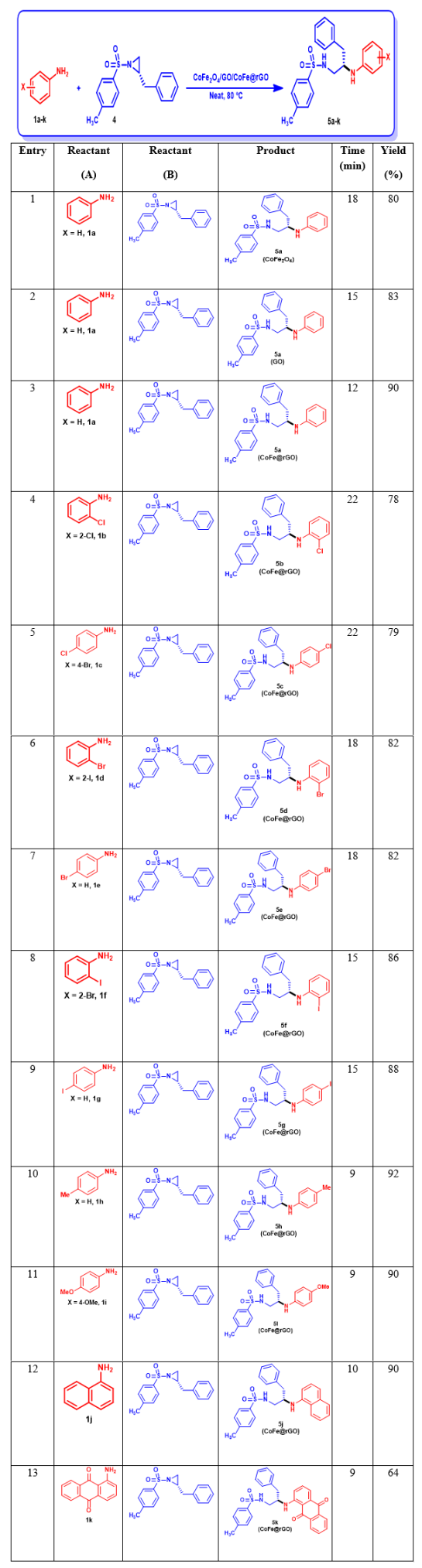

aReagents and conditions: Aniline derivatives (1 mmol), (S)-(+)-2-Benzyl-1-(p-tolylsulfonyl)aziridine (1 mmol), $\mathrm{CoFe}_{2} \mathrm{O}_{4}, \mathrm{GO}$ and CoFe@rGO nanoparticles (10 mg).

Amongst halogens, the iodine substituted amines possessed least reaction time which was followed by bromine and then chlorine derivatives. Moreover, it was observed that the rate of reaction was not affected by the position at which halogens were attached. Among the different types of aziridine, it was speculated that the time taken was quite less for the reactions of unsymmetrical $N$-tosylaziridine with all 
aromatic amines. This can be attributed to the presence of electron releasing $-\mathrm{CH}_{2}-\mathrm{Ph}$ group in the unsymmetrical aziridine which stabilizes the carbocation formed during the activation of aziridine by catalyst ring opening and hence, decreases the reaction time. Moreover, it was observed in table 3 and table 4 that amine $1 \mathrm{k}$ gave product in $65 \%$ and $64 \%$ yield respectively. This can be understood on the basis of structure of 1-aminoanthraquinone which has three aromatic rings that hinder the completion of the reaction. The ${ }^{1} \mathrm{H}$ NMR spectra of products $5 \mathrm{a}-\mathrm{k}$ are given in supplementary file as Fig. S12-S22.

\subsection{Plausible mechanistic pathway:}

Based on the literature survey [46-49], the plausible reaction mechanism for the ring opening of aziridine upon interaction with amine moieties has been proposed in Fig. 7-9. The ring opening of aziridine with aromatic amine was carried out using three different catalysts i.e. Spinel Ferrites, Graphene oxide (GO) and their nanohybrid (CoFe@rGO). The catalytic activity of these catalysts can be accredited to the presence of acidic sites on their surface. Initially, adsorption of aziridine occurs on the surface of catalysts which leads to an increase in the electrophillicity of one of the cyclic carbon atom in the molecule. Further, aryl amine attacks at the more substituted carbon atom of aziridine to give transition state (I), which transfers proton within the molecule to produce the desired product.

\subsection{Recyclability}

The stability of the catalyst is of utmost importance to be utilized in large scale industrial synthetic processes. Due to the magnetic nature of the synthesized nanohybrid, the catalyst could be easily recycled and reused for the ring opening of aziridine. Tremendous stability and recyclability are the noteworthy features of the synthesized CoFe@rGo nanohybrid. After completion of the reaction, the catalyst was recovered from the reaction mixture by an external magnet, washed with distilled water and acetone. The obtained material was then dried and subsequently reused for six catalytic cycles. Even after six catalytic cycles, no significant decrease in the percentage yield was observed for ring opening of $N$-tosylaziridine with aniline indicating excellent reusability of the nanohybrid (Fig. 10). The recovered catalyst was characterized by powder X-ray diffraction and FT-IR, after each catalytic run, no significant change in the nanohybrid was observed signifying high durability of the nanohybrid. The powder XRD pattern and FT-IR spectra of the recovered nanohybrid has been provided in supplementary file (Figs. S25 and S26).

\section{Conclusions}

In conclusion, graphene based magnetic nanohybrid (CoFe@rGO) was successfully synthesized through a facile hydrothermal method and was characterized by various standard techniques. The FT-IR, FE-SEM, XRD and EDX spectroscopic analysis confirmed the proficient fabrication of CoFe@rGO nanohybrid. The formation of single phase cubic structure of $\mathrm{CoFe}_{2} \mathrm{O}_{4}$ with $\mathrm{Fd}-3 \mathrm{~m}$ space group was confirmed by powder XRD pattern and absence of diffraction peak corresponding to (011) plane specified the complete reduction of $\mathrm{GO}$ to $\mathrm{rGO}$ in the nanohybrid. It has been demonstrated that $\mathrm{CoFe}_{2} \mathrm{O}_{4}, \mathrm{GO}$ and $\mathrm{CoFe} @ \mathrm{rGO}$ 
nanohybrid are efficient catalysts for the ring opening of symmetrical and unsymmetrical aziridine with several amines under solvent free conditions. The nanohybrid CoFe@rGO displayed best catalytic activity for the conversion of different aromatic amines to corresponding 1,2-diamines within very short reaction duration. Benzensulfonamides derivatives via ring opening reaction of $N$-Tosylaziridine with different aromatic amines were obtained with good to excellent yields within 10-24 minutes and ring opening of chiral (S)-(+)-2-Benzyl-1-( $p$-tolylsulfonyl)aziridine with different aromatic amines gave products with 64$92 \%$ yields within 9-18 minutes. Due to the magnetic nature of the nanohybrid, the catalyst could be easily separated from the reaction mixture by an external magnet and reused up to six catalytic runs without significant loss of catalytic activity. This developed methodology exhibits numerous remarkable advantages such as eco-friendly and benign conditions, short reaction times, simple work-up, perfect regioselectivity, excellent yields and the use of recyclable and reusable magnetic nanocatalyst. Thus, in near future, the synthesized magnetic nanohybrid could be potentially utilized as green catalyst for the synthesis of several pharmaceutical and intermediate chemicals.

\section{Declarations}

\section{Conflicts of Interest}

There are no conflicts to declare.

\section{Acknowledgements}

The authors are highly thankful to Council of Scientific and Industrial Research (CSIR), India (09/135(0783)/2017-EMR-I) for providing necessary financial support; SAIF-CIL, Panjab University, Chandigarh for the sample characterization.

\section{References}

1. A. Kamal, M.N.A. Khan, K.S. Reddy, K. Rohini, G.N. Sastry, B. Sateesh, B. Sridhar, Bioorg. Med. Chem. Lett. 17, 5400-5405 (2007)

2. X. Zhang, Y. Lin, L. Liu, C. Lin, Luminescence. 30, 269-279 (2015)

3. S. Yotphan, L. Sumunnee, D. Beukeaw, C. Buathongjan, V. Reutrakul, Org. Biomol. Chem. 14, 590-597 (2016)

4. G.M. Brown, J. Biol. Chem. 237, 536 (1962)

5. (a) U.K. Nadir, A. Singh, Tetrahedron Lett. 46, 2083-2086 (2015); (b) J. Aires-de-Sousa, S. Prabhakar, A.M. Lobo, A.M. Rosa, M.J.S. Gomes, M.C. Corvo, D.J. Williams, A.J.P. White, Tetrahedron: Asymm. 12, 3349-3365 (2002); (c) M.T. Hancock, A.R. Pinhas, Tetrahedron Lett. 44, 5457-5460 (2003)

6. J.B. Sweeney, Chem. Soc. Rev. 31, 247-258 (2002)

7. S. Xing, H. Cui, N. Gu, Y. Li, K. Wang, D. Tian, J. Qin, Q. Liu, Org. Biomol. Chem. 15, 8308-8312 (2017) 8. M.K. Ghorai, D.P. Tiwari, N. Jain, J. Org. Chem. 78, 7121-7130 (2013) 
9. X.Y. Yu, Q.Q. Zhou, P.Z. Wang, C.M. Liao, J.R. Chen, W.J. Xiao, Org. Lett. 20, 421-424 (2018)

10. F. Hao, H. Asahara, N. Nishiwaki, Org. Lett. 19, 5442-5445 (2017)

11. D. Tanner, Angew. Chem., Int. Ed. 33, 599-619 (1994)

12. P.W. Smith, J.E. Robinson, D.N. Evans, S.L. Sollis, P.D. Howes, N. Trivedi, R.C. Bethell, Bioorg. Med. Chem. Lett. 9, 601-604 (1999)

13. J. Liu, C. Wang, ACS Catal. 10, 556-561 (2020)

14. S. Tarannum, S. Sk, S. Das, I.A. Wani, M.K. Ghorai, J. Org. Chem. 85, 367-379 (2020)

15. M. Bera, S. Pratihar, S. Roy, J. Org. Chem. 76, 1475-1478 (2011)

16. X. Zhang, S.S. Li, L. Wang, L. Xu, J. Xiao, Z.J. Liu, Tetrahedron. 72, 8073-8077 (2016)

17. X. Li, L. Zheng, N. Li, H. Chang, W. Gao, W. Wei, W. Chen, Chemistry Select 4, 11879-11885 (2019)

18. X. Zhang, X. Qiu, J. Rong, Z. Su, X. Cui, C. Tao, Org. Chem. Front. 6, 1832 (2019)

19. R. Eisavi, S. Alifam, Phosphorus, Sulfur, and Silicon. 193, 211-217 (2018)

20. T. Tamoradi, A.G. Choghamarani, M. Ghadermazi, Solid State Science. 88, 81-94 (2019)

21. S. Pei, Q. Wei, K. Huang, H.M. Cheng, W. Ren, Nat Commun. 9, 145 (2018)

22. S. Yadav, N. Goel, V. Kumar, K. Tikoo, S. Singhal, Environ. Sci. Pollut. Res. 25, 2942-2957 (2018)

23. M. Daraie, M.M. Heravi, S.S. Kazemi, Journal of Coord. Chem. 72, 2279-2293 (2019)

24. A. Sheoran, J. Kaur, P. Kaur, V. Kumar, K.B. Tikoo, J. Agarwal, S. Bansal, S. Singhal, J. Mole. Struct. $1204,127522(2020)$

25. N. Kausar, P. Mukherjee, A.R. Das, RSC Adv. 6, 88904 (2016)

26. R. Jamatia, A. Gupta, A.K. Pal, ACS Sustainable Chem. Eng. 5, 7604-7612 (2017)

27. Y.H. Liu, H.C. Hu, Z.C. Ma, Y.F. Dong, C. Wang, Y.M. Pang, Monatsh. Chem. 149, 551-556 (2018)

28. M.Z. Ansari, M. Shoeb, P.S. Nayab, M. Mobin, I. Rahisuddin, W.A. Khan, Siddiqi, J. Alloy. Compo. 738, 56-71 (2018)

29. S. Yadav, S. Singh, N. Goel, S. Singhal, Appl. Surf. Sci. 497, 143761 (2019)

30. A. Alazmi, V. Singaravelu, N.M. Batra, J. Smajic, M. Alyami, N.M. Khashab, P.M.F.J. Costa, RSC Adv. 9 , 6299-6309 (2019)

31. S. Sheshmani, B. Falahat, F.R. Nikmaram, Int. J. Biol. Macromol. 97, 671-678 (2017)

32. W. Wang, S. Guo, D. Zhang, Z. Yang, J. Saudi Chem. Soc. 23, 133-140 (2019)

33. R. Shu, G. Zhang, J. Zhang, X. Wang, M. Wang, Y. Gan, J.J. Shi, J. He, Mater. Lett. 215, 229-232 (2018)

34. S. Bai, X. Shen, X. Zhong, Y. Liu, G. Zhu, X. Xu, K. Chen, Carbon. 50, 2337-2346 (2012)

35. Z. Shahnavaz, P.M. Woi, Y. Alias, Ceram. Int. 41, 12710-12716 (2015)

36. M.M. Mohamed, I. Ibrahim, T.M. Salam, Appl. Catal. A: Gen. 524, 182-191 (2016)

37. S. Kapoor, V. Kumar, K.B. Tikoo, B. Chudasama, N. Goel, S. Singhal, Ceram. Int. 46, 2724-2742 (2019)

38. Y. Koaeoglu, F. Alan, M. Tan, R. Yilgin, M. Ozturk, Ceram. Int. 38, 3625-3634 (2012) 
39. Y. Yıldız, S. Kuzu, B. Sen, A. Savk, S. Akocak and F. Şen, Int. J. hydrog. Energy. 42, 13061-13069 (2017)

40. S. Eris, Z. Daşdelen, Y. Yıldız, F. Sen, Int. J. Hydrog. Energy. 43, 1337-1343 (2018)

41. K. Karami, N.S. Mousavi, Dalton Trans. 47, 4175-4182 (2018)

42. Kausar, P. Mukherjee, A.R. Das, RSC Adv. 6, 88904-88910 (2016)

43. A. Goyal, S. Kapoor, P. Samuel, V. Kumar, S. Singhal, RSC Adv. 5, 51347-51363 (2015)

44. H.Y. Xu, B. Li, T.N. Shi, Y. Wang, S. Komarneni, J. Colloid inter. Sci. 532, 161-170 (2018)

45. A. Sheoran, M. Dhiman, S. Bhukal, R. Malik, J. Agarwal, B. Chudasama, S. Singhal, Mater. Chem. Phy. 222, 207-216 (2019)

46. M. Meguro, N. Asao, Y. Yamamoto, J. Chem. Soc. Perkin Trans. 1, 2597-2601 (1994)

47. F. Carree, R. Gill, J. Collin, Tetrahedron Lett. 45, 7749-7751 (2004)

48. T. Ollevier, G.L. Compin, Tetrahedron Lett. 45, 49-52 (2004)

49. U. Das, B. Crousse, V. Kesavan, D.B. Delpon, J.P. Begue, J. Org. Chem. 65, 6749-6751 (2000)

\section{Scheme}

Scheme 1 is included in the Supplementary Files section.

\section{Figures}

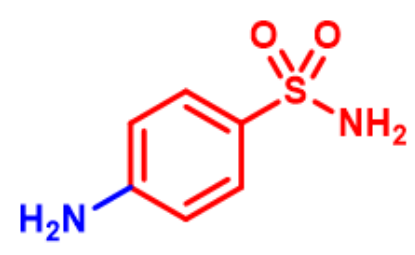

Sulfonylamide

Antibacterial drug<smiles>O=C(NS(=O)(=O)c1ccc(Cl)cc1)c1ccc(Cl)cc1Cl</smiles>

Acylsulfonamide

Antitumor agents<smiles>CC(=O)Nc1ccc(S(=O)(=O)NNC(=O)c2ccccc2Nc2ccccc2)cc1</smiles>

Nicotinyl arylsulfonyl hydrazide Antitumor agents

Figure 1

Biological activities of sulfonamides. 


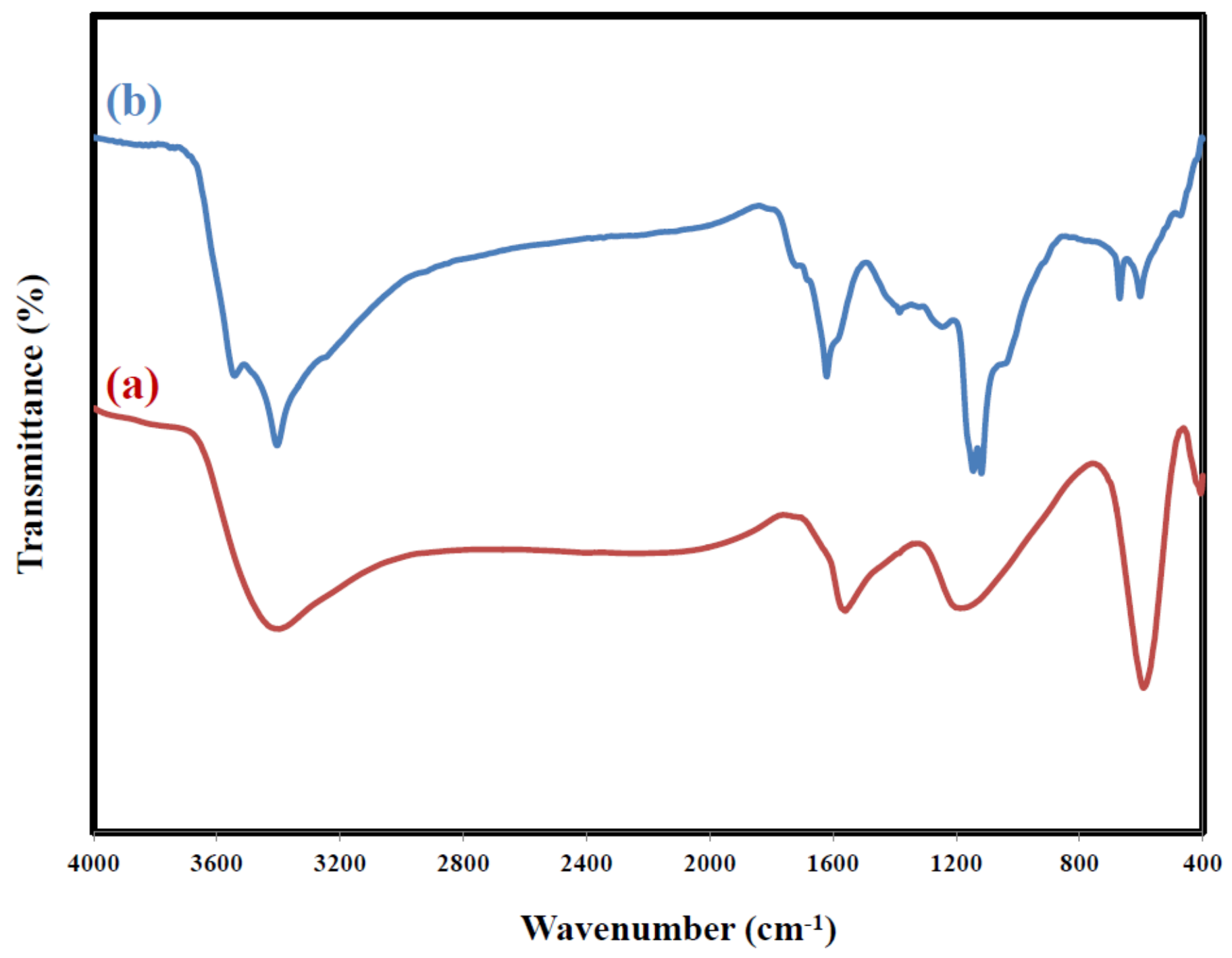

Figure 2

FT-IR spectra of (a) CoFe@rGO nanohybrid and (b) GO. 


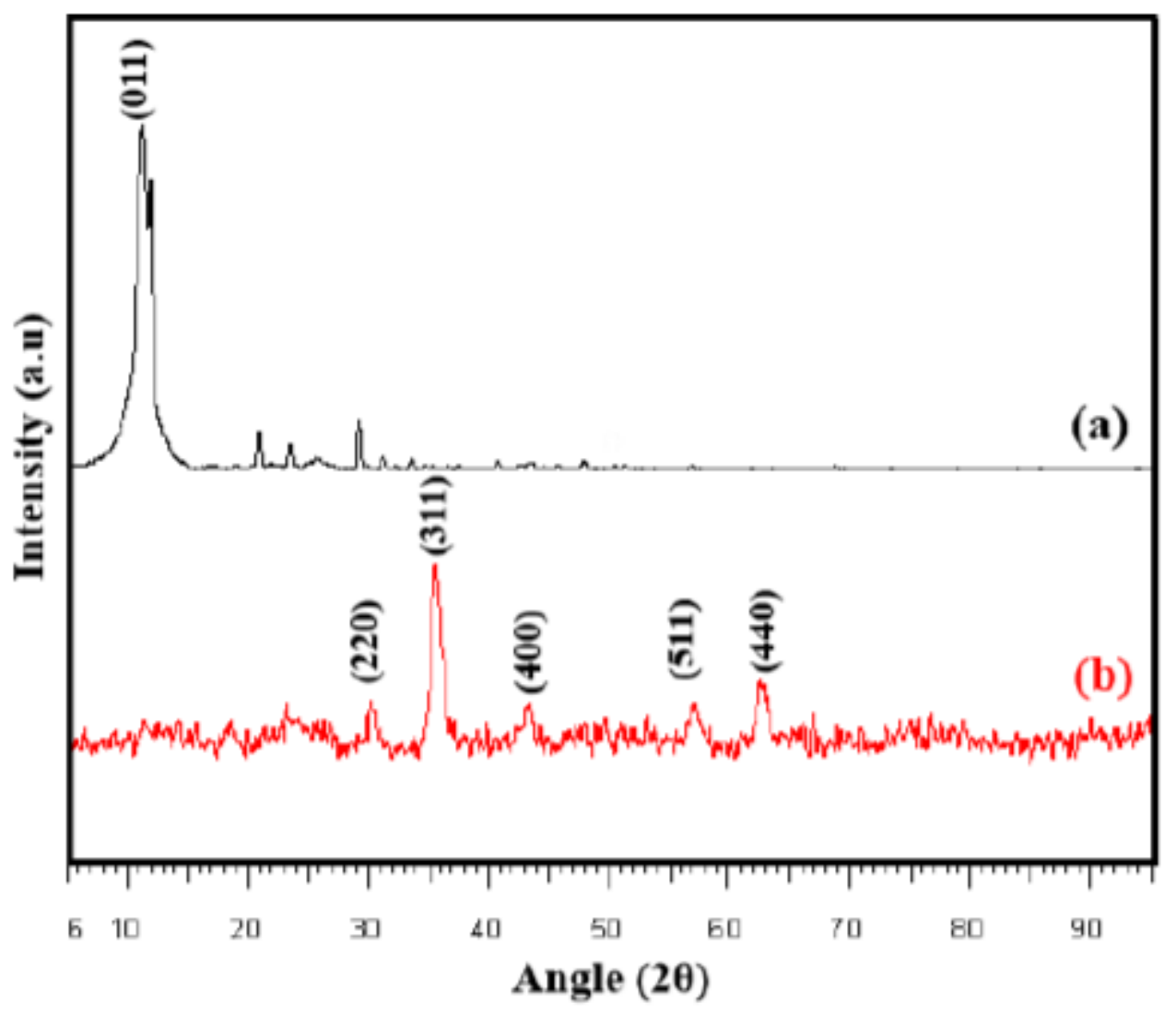

Figure 3

Powder XRD patterns of (a)GO and (b)CoFe@rGO nanohybrid. 


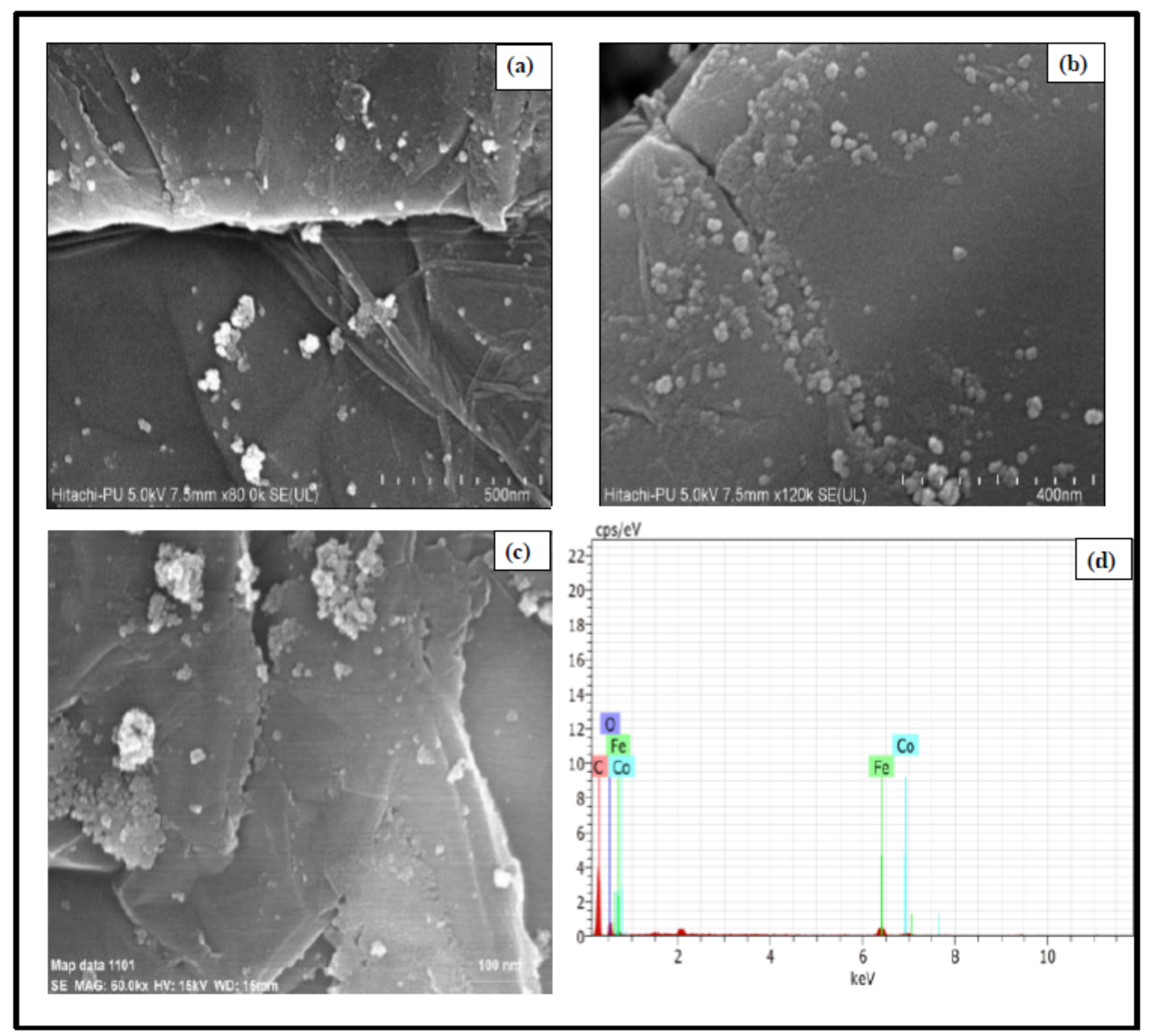

Figure 4

Typical FESEM micrographs at (a) 500nm, (b) 400 nm, (c) 100 nm and EDX spectra (d) of CoFe@rGO nanohybrid. 


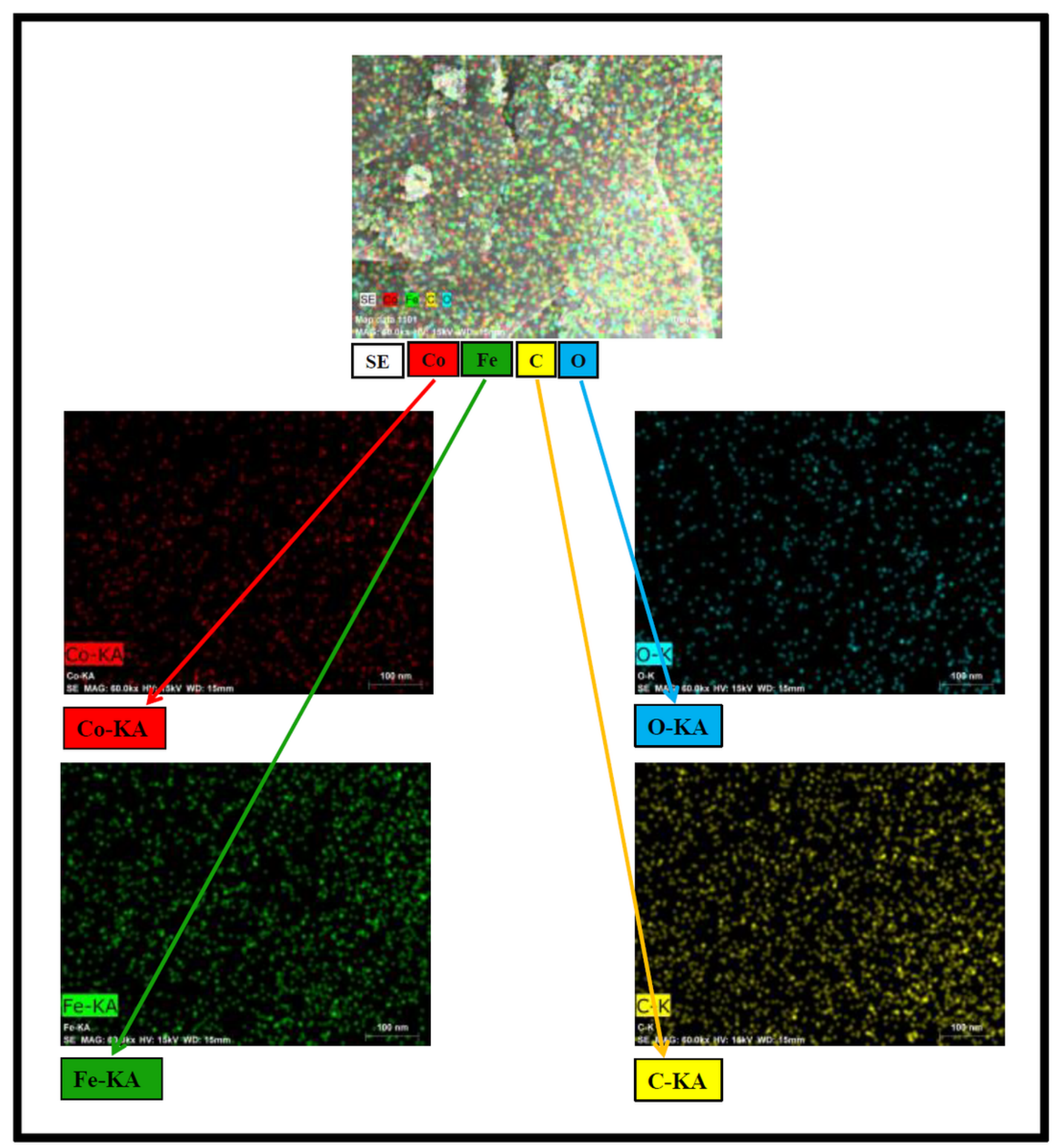

Figure 5

Elemental mapping of CoFe@rGo nanohybrid. 


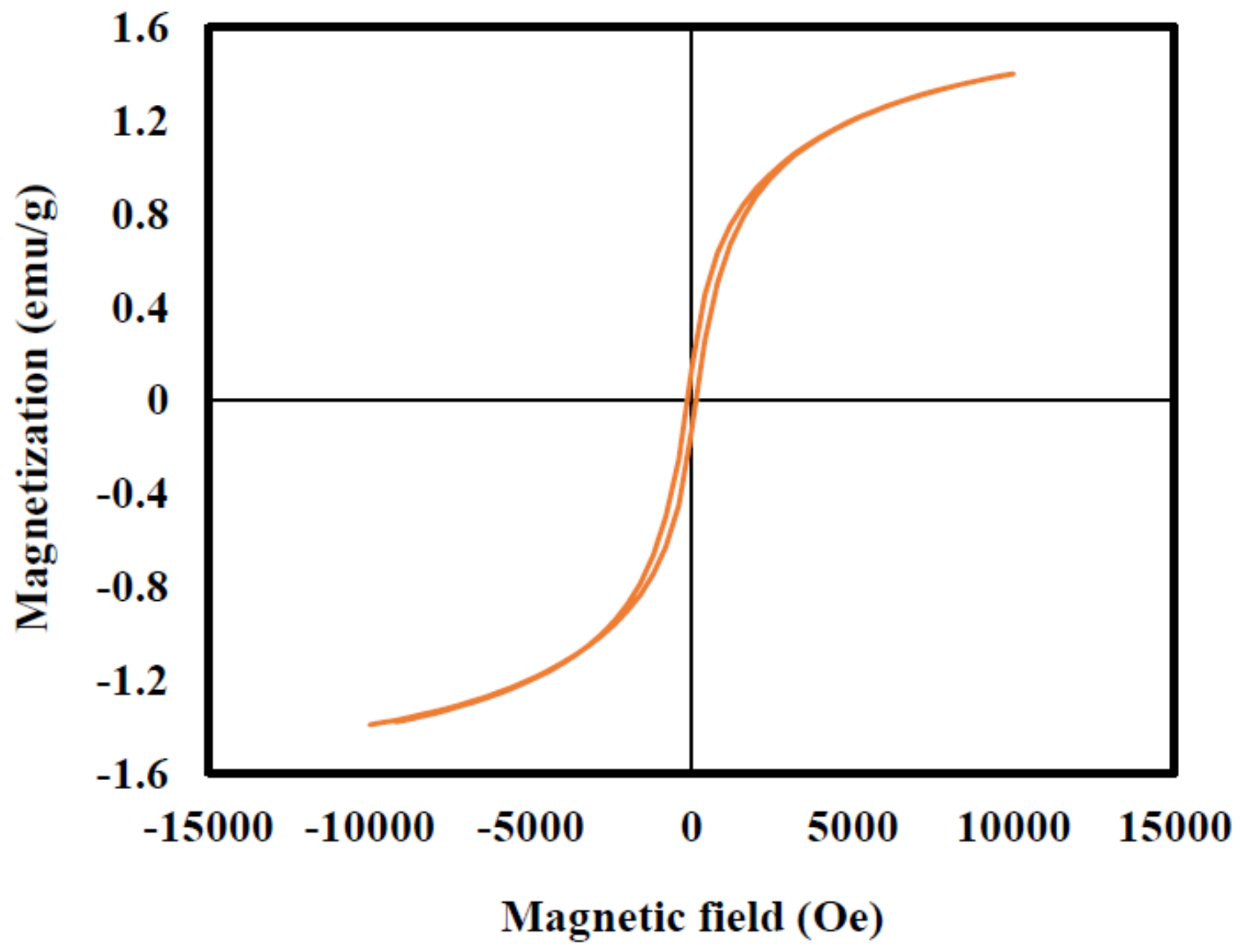

Figure 6

Room temperature hysteresis loop for CoFe@rGo nanohybrid. 


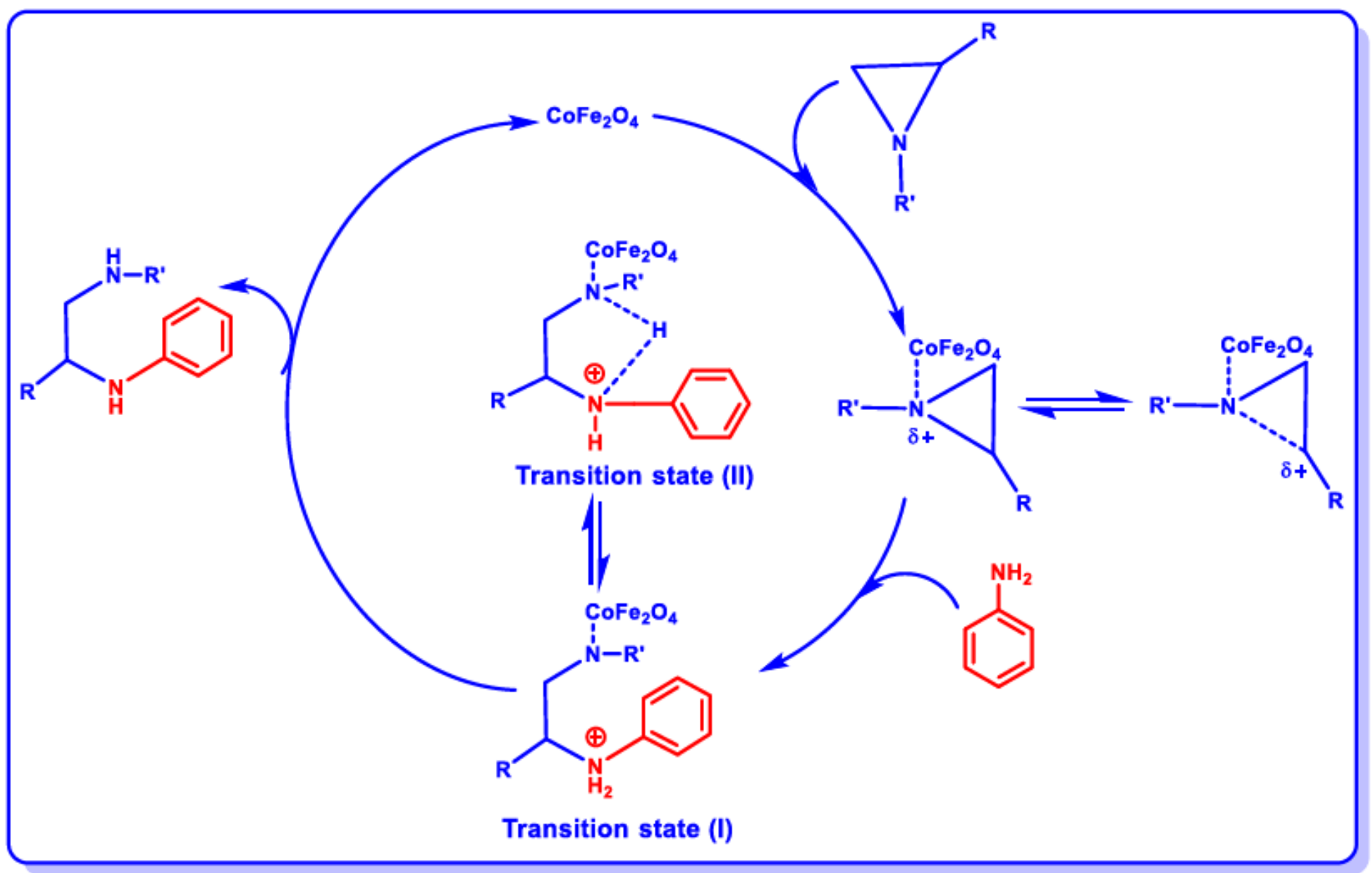

Figure 7

Schematic representation of the reaction mechanism for the aziridine ring opening using CoFe2O4 as catalyst. 


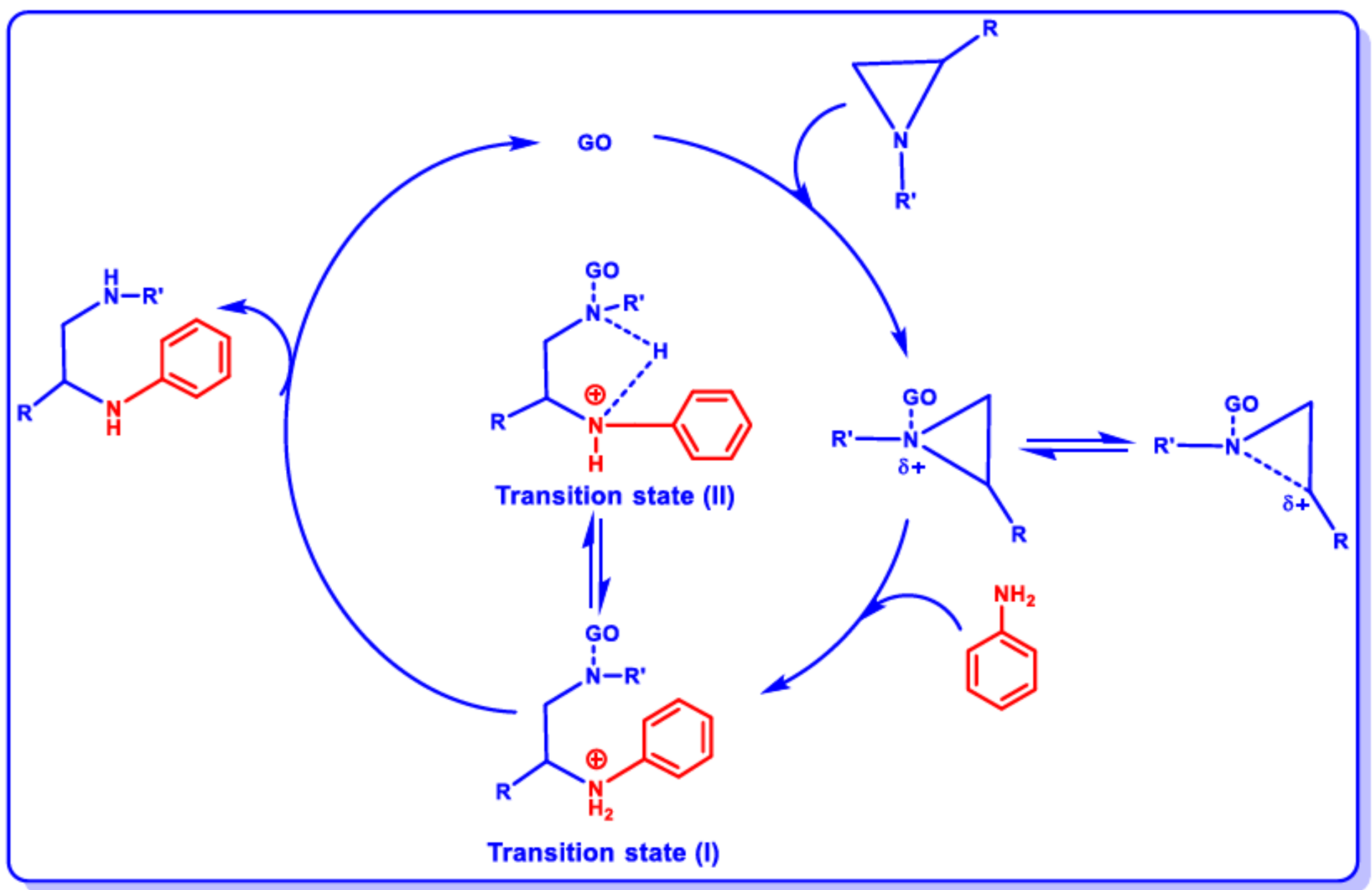

Figure 8

Schematic representation of the reaction mechanism for the aziridine ring opening using GO as catalyst. 


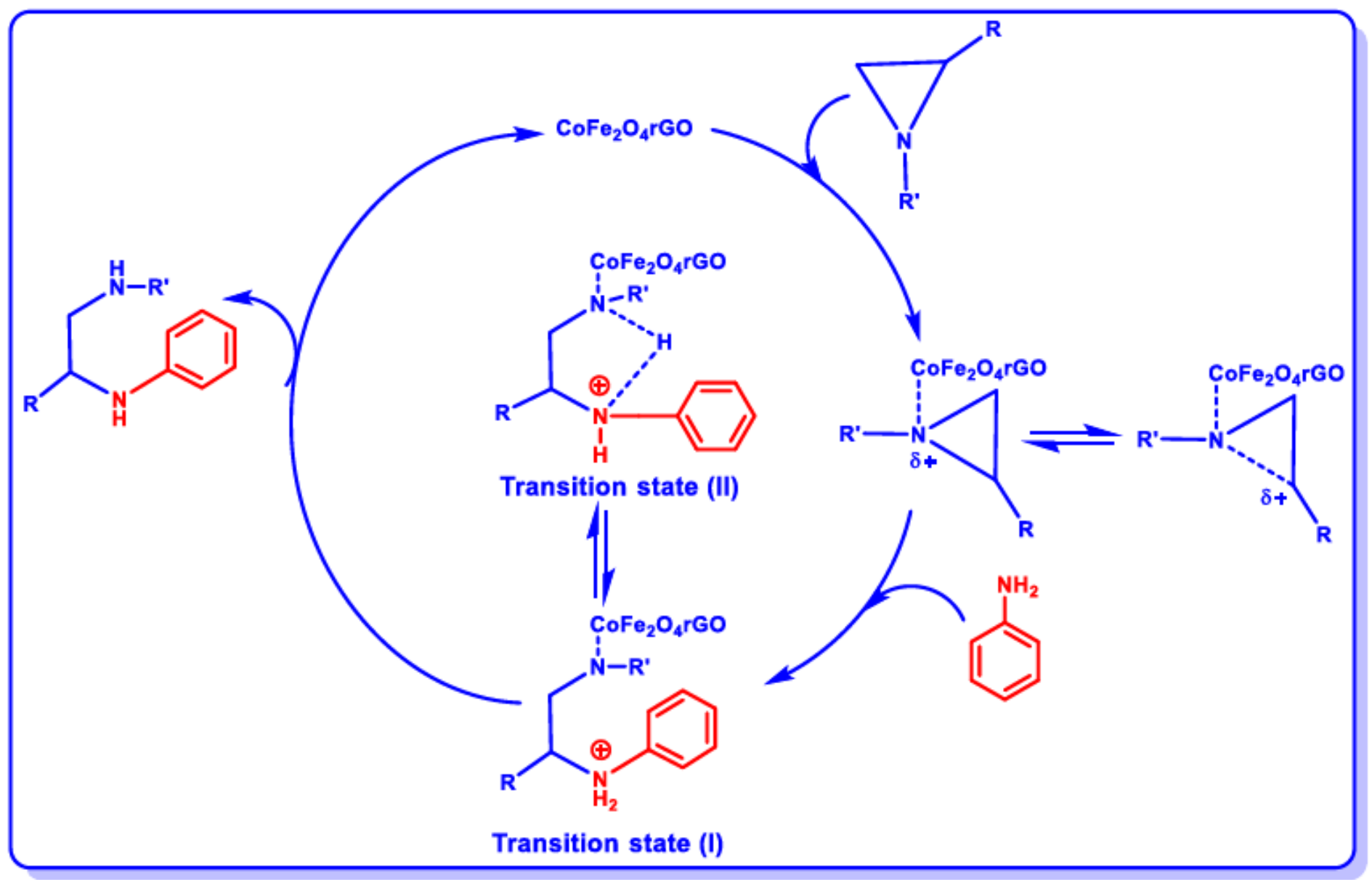

Figure 9

Schematic representation of the reaction mechanism for the aziridine ring opening using CoFe@rGo nanohybrid as catalyst. 


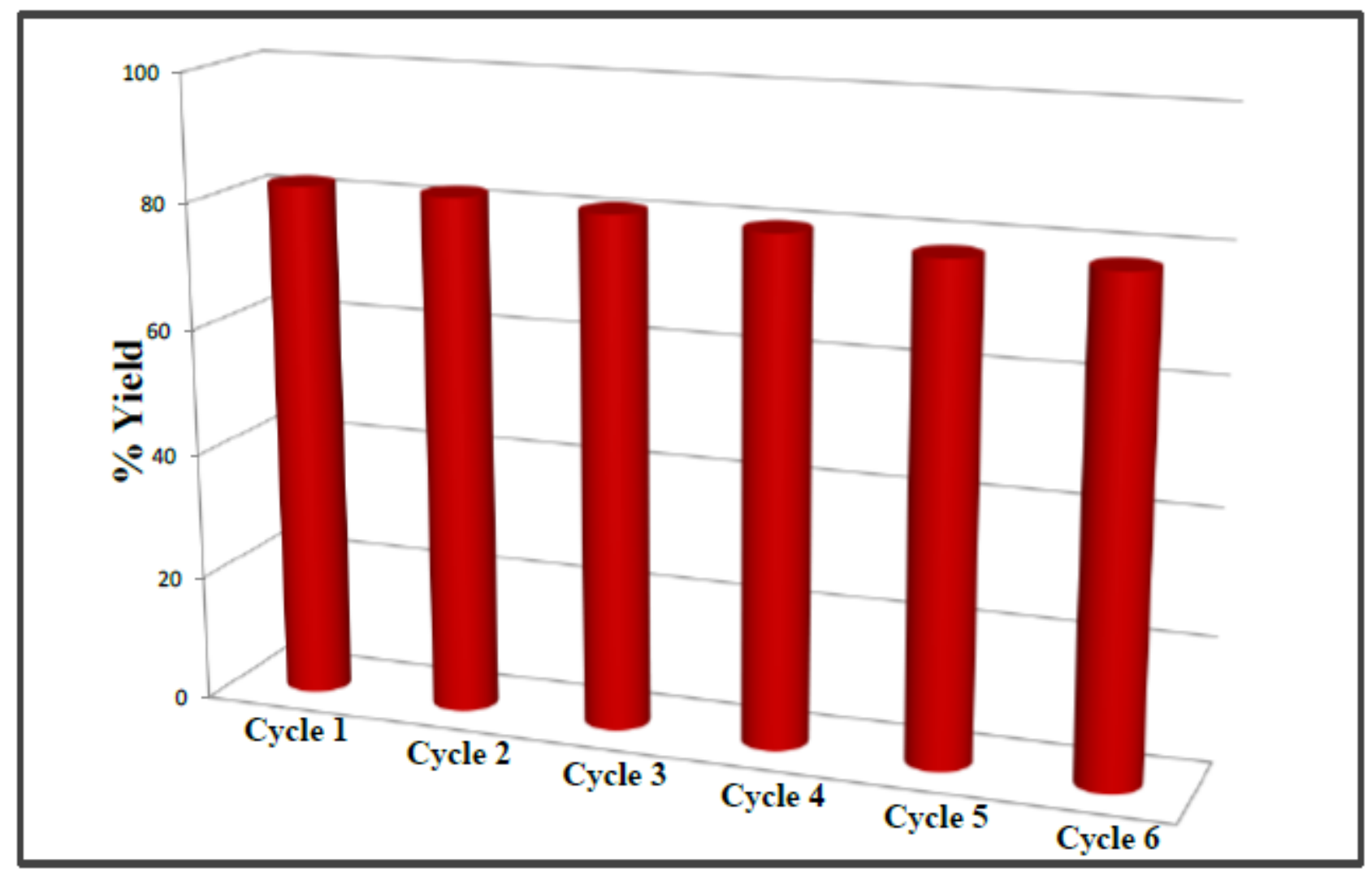

Figure 10

Typical recyclability plots for CoFe@rGo nanohybrid for the ring opening N-tosylaziridine with aniline.

\section{Supplementary Files}

This is a list of supplementary files associated with this preprint. Click to download.

- GraphicalAbstract.png

- Scheme1.png

- Supplementaryfile.docx 